\title{
THE FEM APPLICATION IN NUMERICAL ANALYSIS OF SLEWING RINGS ROLLER/BALL COMBINATION BEARING
}

\begin{abstract}
Slewing bearings are selected based on the characteristics of capacity, which determine the area of the permissible load of the bearing. This capacity of a bearing does not take into account the real operating conditions of a bearing. This implies a necessity to take into consideration all the factors having an influence on the bearing capacity during its determination. The way of determining of the static limiting load curves profiles (static capacity chart) of a double-row roller/ball combination slewing bearing is presented in this article. In the calculations, taking into account flexural-torsional flexibility of bearing rings, flexibility and number of bearing clamping bolts and the most important parameters of the contact zone of rolling elements with bearing raceways, is presented in the paper. Concluding results have been obtained in numerical way. Distribution of internal load, which is in individual rows of a bearing, is presented here. Basic problems of modelling the component unit of the slewing bearing are discussed. In calculating the profile, the initial clamp of the fixing bolt, flexible rings, flexible casing and variation of the contact angle bearing are allowed for. Particular attention is paid to modelling of elements that are equivalent for balls bearing. Obtained results are presented as graphs.
\end{abstract}

Keywords: FEM, slewing bearing, load bearing capacity, load distribution

\section{Introduction}

The rotation mechanisms of lifting devices are usually constructed with the use of slewing roller bearings. These are the sub-assemblies of machines that carry the entire load resulting from their operation. Due to the high load capacity, relatively compact construction and small dimensions, they are used not only in classic machinery and equipment such as excavators, all types of cranes and other construction machinery, military vehicles but are widely used in wind power plants, rail vehicles and many other devices, as well (Figure 1) [1].

The slewing bearing load capacity usually limits the maximum external loads of the designed machine and the correct estimation of it is an important part of the working machine calculation. Slewing bearings are usually selected for extreme loads, so that their work is at the limit of endurance. This requires careful and precise calculations of their performance parameters, of which still the most important is the static load capacity, more and more often supplemented by additional criteria like assembly, durability, determination of movement resistance etc. [2].

\section{The load rating of a slewing bearing}

The selection of a bearing is made based on its static capacity in the conditions of typical work of a slewing bearing in working machines. The static capacity is determined based on the strength criterion in the contact zone of the rolling elements and the bearing raceways. In this paper, the criterion of limiting relative plastic deformation was taken from Eschmann [3]:

$$
\frac{\delta_{p l \text { lim }}}{d}=2 \cdot 10^{-4}
$$

The permissible load of rolling elements was established based on the empirical equations of Brändlein and others [3], adequately for the point contact:

$$
\frac{\delta_{p l}}{d}=\left(\frac{p_{0}}{2550 \sqrt[3]{c_{p}}}\right)^{5}
$$

where:

$$
\frac{\delta_{p l}}{d}=\left(\frac{p_{0}}{2550 \sqrt[3]{c_{p}}}\right)^{5}
$$

\footnotetext{
* Marek Krynke, Piotr Sygut

Czestochowa University of Technology, Department of Production Engineering and Safety, Poland

E-mail: krynke@zim.pcz.pl
} 


\section{KOMNIKOCle}
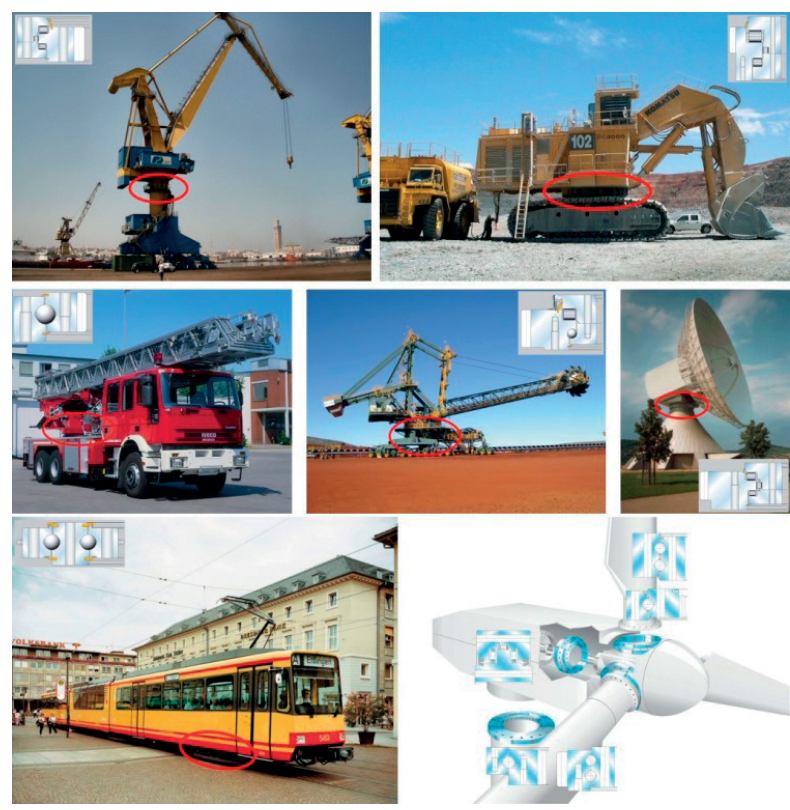

Figure 1 Examples of the slewing bearings applications

$c_{p}=\frac{1.5}{\pi \mu_{H} v_{H}}\left[\frac{E}{3\left(1-v^{2}\right)} d \Sigma \rho\right]^{\frac{2}{3}}$

and for the linear contact:

$$
\frac{\delta_{p l}}{d}=\left(\frac{p_{0}}{1003.3 \sqrt{c_{p L}}}\right)^{5}
$$

where:

$$
\begin{aligned}
p_{0} & =c_{p L} \sqrt{\frac{F}{d l_{e}}} \\
c_{p L} & =\sqrt{\frac{E}{\pi\left(1-v^{2}\right)} \frac{d \Sigma \rho}{2}}
\end{aligned}
$$

Relationships (2) and (5) were determined for common bearings with a hardness of rolling elements and a raceway equals $62 \mathrm{HRC}$, what corresponds to $\mathrm{HV} \approx 750$. In the slewing bearings the hardness of raceway is lower, for hardened raceways is equals $50 \div 56 \mathrm{HRC}$, therefore the hardness of a raceway takes into account the hardness factor $f_{H}$ :

$$
f_{H}=\left(\frac{H V}{750}\right)^{2}
$$

For steel the Young's modulus is $\mathrm{E}=2.08 \cdot 10^{5} \mathrm{MPa}$ and the Poisson's ratio is $v=0.3$, thus, the limiting values of the load of the rolling elements are obtained based on the above equations as: for the point contact

$$
F_{\lim }=9.9626 \cdot 10^{7} \frac{f H d^{2}}{c_{p}^{2}}
$$

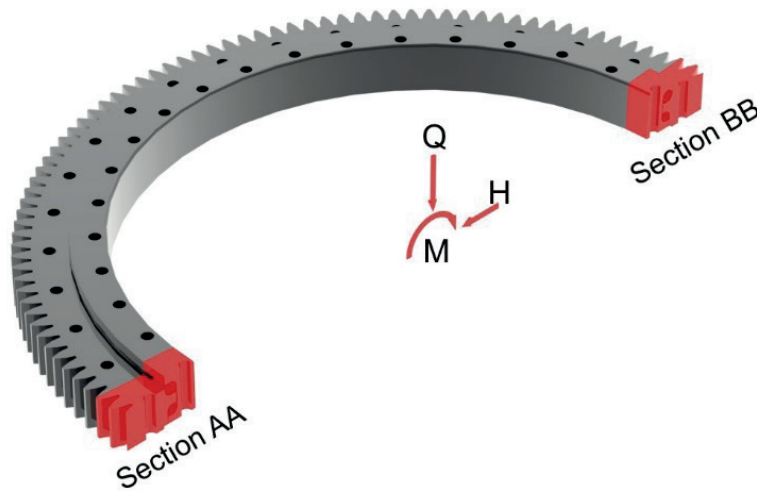

Figure 2 Components of external load of a slewing bearing

for the linear contact

$$
F_{\mathrm{lim}}=123.57 f_{H} d l_{e} \sqrt{1-\frac{d}{2 a_{0}} \cos \alpha}[\mathrm{N}]
$$

The slewing bearing can be loaded by three components of the external load as it is shown in Figure 2. Two pairs of raceways are distinguished in every slewing bearing. Together with cooperating rolling elements they are called the computation rows of the bearing. The row, where interactions from the axial force $Q$ and the tilting moment $M$ are summed up, is called the capacity row and the second row-the support row.

Regardless of the method of the load imposing, the computations of capacity are carried out applying an iteration method. The distribution of the internal load of a bearing is computed and the maximum value of the load of rolling element in every row of a bearing is searched for the assumed value of the internal load. The strength condition of correct work of a bearing is as follows:

$F_{i, j} \leq F_{\lim j}$

where: $i$ is the index of the rolling part in the j-th row.

Iteration is interrupted if the maximum load of one of the rolling parts $F_{\text {max } j}$ fulfils condition

$$
F_{\max j}=F_{\lim j}
$$

in optional row (for the assumed accuracy of computations).

\section{The double-row slewing rings roller/ball combination bearings}

The double-row slewing rings roller/ball combination bearings (Figure 3) are aimed for applications with small eccentricities at relatively high axial loads, which call for a long service life, even with continuous oscillating motions, and where the structural 


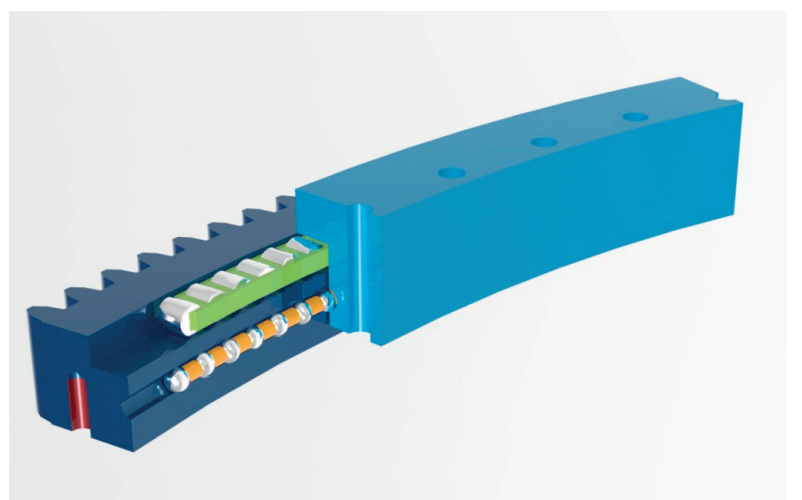

Figure 3 The double - row slewing rings roller/ball combination bearing

design requires a large bearing diameter. For this bearing type, the eccentricity:

$k=\frac{2 M}{D Q}$

should not exceed 1.2 under operating loads. If in extreme static cases,$k$ is found to be higher than 2 , an accurate verification would be required.

The entire load capacity ranges, which lie under the static load limiting curve and the operating load curve, are covered by use of the grade 10.9 bolts [4].

Calculations of the load capacity profiles of slewing bearings were made for a double-row slewing rings roller/ball combination bearing with the parameters as presented in Table 1 .

\section{The numerical model of the slewing bearing}

The slewing bearing is a complex construction. The numerical model of the bearing is made using the FEM. ADINA software was applied to this [5]. Two groups of problems can be distinguished during the model building: bearing modelling on a macro scale, it means modelling bearing rings and their mounting and modelling bearing on a local scale, it means modelling phenomena in the contact zone of rolling elements and bearing raceways.

Huge number of contact zones is present in the slewing bearing (quite often a few hundred). To avoid unwanted increase in the size of the numerical model, the rolling elements in the bearing are substituted by the so-called super-elements introduced in works [6]. The linear element with the nonlinear characteristics, which is determined based on equivalent characteristics of the contact zone [7], is the main fragment of the super-element. The equivalent characteristics take into account a reduction in the distance of bearing rings caused by the load and results of connection of the truss element with the mesh built of the 3D elements (the so-called effect of concentrated force). The first stage of modelling a slewing bearing is the computation of the equivalent characteristics of the rolling elements. Those
Table 1 Parameters of slewing bearings analysed in the study

\begin{tabular}{cccc}
\hline Bearing parameter & & $\begin{array}{c}\text { carrying row } \\
\text { (roller) }\end{array}$ & $\begin{array}{c}\text { supporting } \\
\text { row (ball) }\end{array}$ \\
\hline $\begin{array}{c}\text { Rolling diameter of a } \\
\text { calculation row [mm] }\end{array}$ & $d_{t}$ & 3550 & 3506 \\
$\begin{array}{c}\text { Diameter of rolling elements } \\
\text { [mm] }\end{array}$ & $d$ & 32 & 25 \\
$\begin{array}{c}\text { Number of rolling elements in } \\
\text { the calculation row, }\end{array}$ & $z_{I}$ & 304 & 304 \\
Roller length [mm] & $l_{l}$ & 30 & - \\
Contact coefficient & $k_{p}$ & - & 0.96 \\
Operation angle [ ${ }^{\circ}$ ] & $\alpha_{0}$ & 90 & 45 \\
Race hardness [HRC] & & 54 & 54 \\
\hline
\end{tabular}

characteristics depend mainly on the sizes and parameters of the contact zone, as well as on the discretization method of bearing rings. Basically, they should be determined separately for each bearing, but a certain set of the typical characteristics of the rolling elements for the same sizes of the elements and similarity in shape of intersection of bearing rings can be prepared.

Rollers were substituted by the non-linear springs connected to nods of a mesh of bearing rings, as was applied in the numerical modelling in $[8,9]$.

In ball slewing bearings super-element additionally should simulate the change in operating angle of a bearing. The change in operating angle results from deformation of the contact zone under the load and from clearances in a bearing [10]. The superelement consists of the two truss elements of the high rigidity, connected to the node of the bearing ring at one of the ends. The second ends of these elements are placed in the centre of curvature of the bearing raceway profile and they are connected to the linear element with the non-linear characteristics determined based on the equivalent characteristics of the contact zone. Various forms of this type of super-elements applied in modelling of a slewing bearings were presented in work [11].

The relation between the deformation of each ball bearing and the force which produces it is given by the contact rigidity, which is a non-linear function of the material of the ball bearing and raceway and of the relative displacement between them [12].

In the analytical calculations of the slewing bearings, the basic parameter for deformations in the contact zone is accepted as the mutual approach of the bearing rings $\eta$ under the acting of the force F. It is for this parameter's purpose that it is the most convenient to use the equation:

$$
\eta=c F^{w}
$$

The value of the exponent $w$ is the measure of the "nonlinearity" of the deformation-load characteristics. In analytical calculations the exponent $\mathrm{w}$ is usually assumed to be $\mathrm{w}=0.9$ for the roller bearing and $\mathrm{w}=2 / 3$ for the ball bearing. 


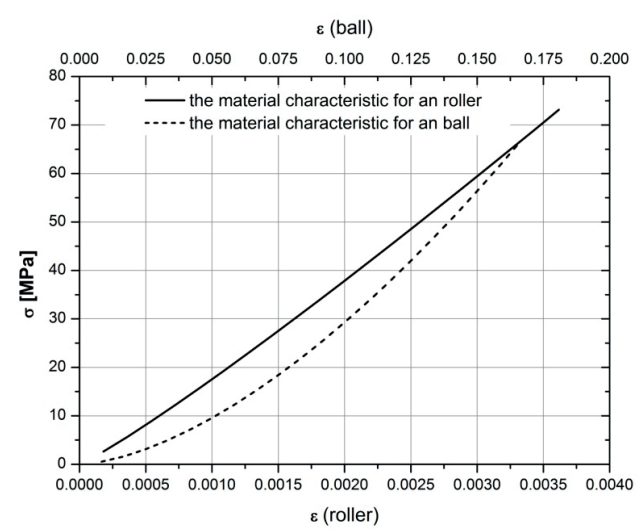

Figure 4 Equivalent characteristics of rollers and balls

The length of elastic element for rollers equals

$l_{T}=d$

and for balls

$l_{T}=d\left(\frac{1}{k_{p}}-1\right)$

The non-linear characteristics of the truss element in superelement are computed according to conditions of applied FEM software. For the FEM calculating programs such as ADINA, the load-deformation characteristic should be noted as a stressstrain dependency. The ADINA program allows for the use an elastic material with a nonlinear characteristic for truss elements [5]. Such materials are used in this analysis. Figure 4 shows the schematic nonlinear characteristics $\sigma-\varepsilon$. The truss element modelling a roller transmits only the compressive forces. The computational cross-section area of the element $A_{t}$ can be determined based on the replacement section, which, for the rollers and balls respectively, is given as:

$$
A_{t}=\frac{F_{\max }}{d l_{e}} \text { and } A_{t}=\frac{F_{\max }}{d^{2}}
$$

The individual points of the material characteristics are determined by the equation for stress:

$$
\sigma_{i}=\frac{F_{i}}{A_{t}}
$$

and for strain

$$
\varepsilon_{i}=\frac{\eta_{i}}{l_{T}}
$$

Figure 4 presents the non-linear characteristics of the truss element in the ball bearing computed for the ADINA software.

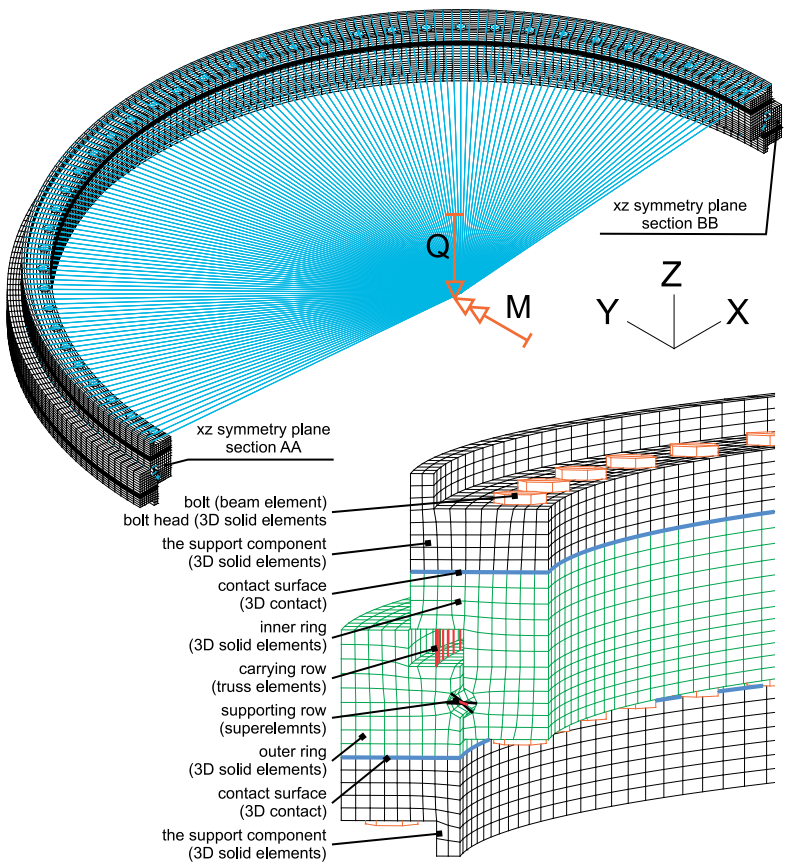

Figure 5 Mesh of the numerical model of a double - row roller/ball combination slewing bearing (with sectional rings) and boundary condition

The numerical modelling of a bearing on a macro scale is reduced to preparation of mesh of bearing ring models, acceptance of shape of mounting elements and acceptance of the method of modelling the bearing clamping bolts. Constructional details of elements to which a bearing is mounted are not known at the stage of computations of the catalogue capacity. It was assumed that the bearing rings are fastened to the ring-girders [9].

The 8-nod elements of 3D-SOLID type were applied to discretization of bearing rings. The following simplifications of the shape of bearing rings were introduced to model the bearing rings:

- toothing of bearing rings was not considered,

- small constructional details, such as grooves for gaskets, grease holes, etc., were not considered,

- holes for clamping bolts were not considered.

The last of the above simplifications is related to the modelling method of clamping bolts of a bearing. Full models of the bolt joints were not done to decrease the size of model. It was assumed that the bolts are modelled using the beam elements. This allows to introduce an initial tension in bolts. To achieve this, elements of the BOLT type are applied in the ADINA software.

The method of modelling the bearing rings and clamping bolts is shown in Figure 5 on the example of the mesh of a model of a three-row roller bearing. Segmentation of rings over the circuit is regular and mesh density is conditioned by the arrangement pitch of the rolling elements.

Due to symmetry of the problem (tilting moment is acting in the plane determined by axial and radial load) only a half of the ring structures was taken for computation. In the plane of division 


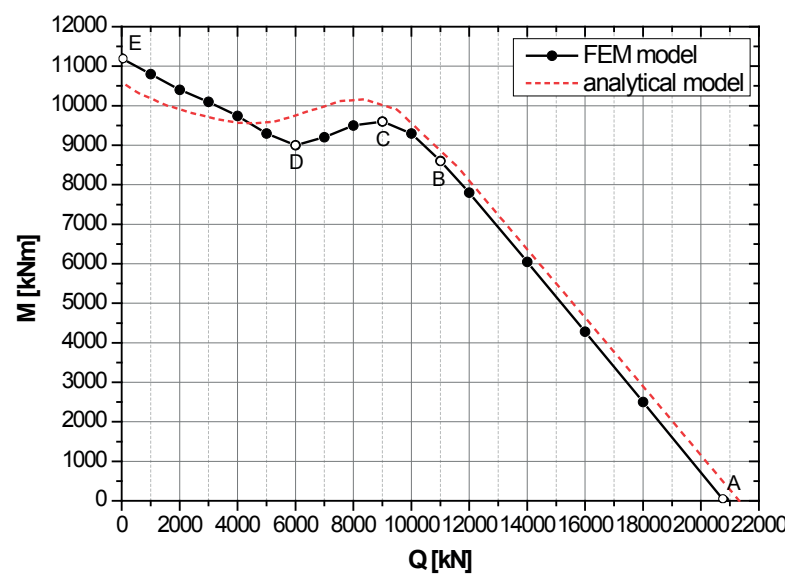

Figure 6 Characteristics of a double - row roller/ball combination slewing bearing with parameters from Table 1

of rings, the adequate constraints resulting from symmetry were applied. One of the girders of a bearing mounting is fastened at its bottom plane. It is called the support girder. The load is imposed on the second girder-called the load girder.

\section{Results of calculation of the load capacity and analysis}

Figure 6 presents the charts that illustrate the static load capacity profiles for the slewing bearings a roller/ball combination slewing rings. The charts also show the scopes of specific cases of bearings operation for nominal states (without play). In the $\mathrm{AB}$ range, the load capacity is determined by the load capacity of a row, which is limited by the permissible force $F_{\text {llim }}$ of a rolling element, which is present in the bearing node (section BB in Figure 2). The bearing node it is the sector of the bearing in the plane where the torque $\mathrm{M}$ is applied.

The $\mathrm{AB}$ range is the place where only the rolling elements of the load-carrying row are operating, while the rolling parts in the supporting row do not take part in transferring the external load. The rolling elements of the supporting row, which are present in the section AA (point C) they begin to carry small loads. At point $\mathrm{D}$ occurs a slight decrease in the bearing load capacity, due to the fact that the number of the rolling elements in the carrying row is significantly reduced. At the same time rolling elements in a supporting row are used to a small degree. In the range DE, there is an increase of the bearing capacity, which is derived from the large participation of the supporting row in the transmission of external loads.

Figure 7 presents the charts that illustrate distribution of internal load in the bearing for these specific operation points. At the point $\mathrm{A}$, where the bearing transfers only axial forces, the load capacity is determined by the strength of the support row. This results from the higher operating angle of rolling elements

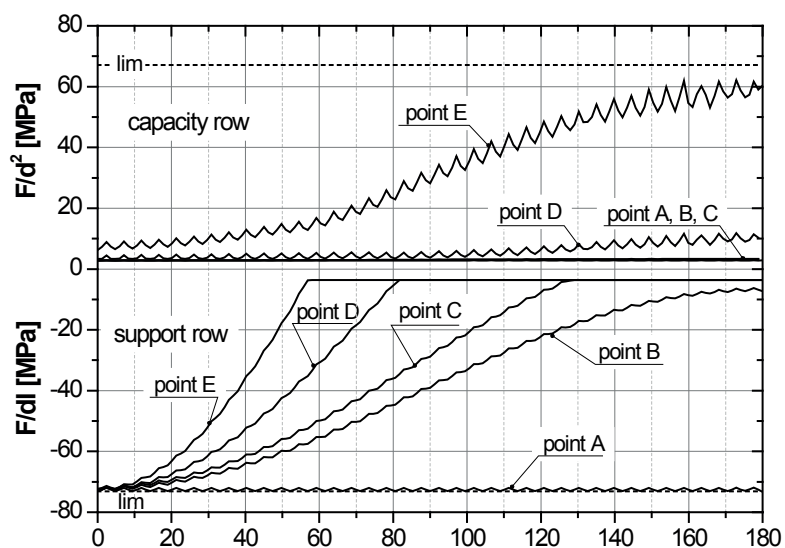

Figure 7 Distributions of the internal load in a double - row roller/ball combination slewing bearing for individual points $A, B, C, D$ marked in Figure 6

in the bearing with play. The $\mathrm{AB}$ range is the place where all the rolling elements of the load-carrying row are operating, while the rolling parts in the supporting row do not take part in transferring the external load. From the point B on, the rolling elements in the supporting row start to operate; thus, an insignificant decline in the profile at this point (Figure 7). An additional increase in the load capacity occurs in the $\mathrm{BC}$ range due to even greater use of the rolling parts in the supporting row. Another decline in the profile is observed at point $\mathrm{C}$ (Figure 6).

The load capacity reduces until it reaches the point $\mathrm{D}$ with the lowest value. In the load area of the section $\mathrm{CD}$, the play between the rolling elements and races causes that the active sections of the bearing's race are reduced with relatively insignificant use of the rolling elements in the supporting row; hence a decline in the load capacity in this range of load. An increase in the load capacity is observed in the DE range, which is caused by the higher contribution of the load capacity of the supporting row until it reaches the value at point $\mathrm{E}$, where the rolling parts, present in the bearing node BB, reach the permissible load $F_{\text {limin }}$.

Figure 8 shows the successive positions of the bearing ring, for each load point.

The next positions of bearing ring, were determined for individual points of its carrying capacity characteristics. As a result of power $Q$ effects and $M$ moment, there follows the axial transfer, radial and rotation of the ring in a plane of turning moment action.

The radial displacement results from the angle of balls action in the row supporting, which in the nominal state (i.e. in unbiased bearing is $45^{\circ}$ ) (Figure 8). As a result of the load transferred through the rolling elements in the supporting row, follows a change of the nominal angle value of their action. The maximum ranges of these changes are presented in Figure 9. 


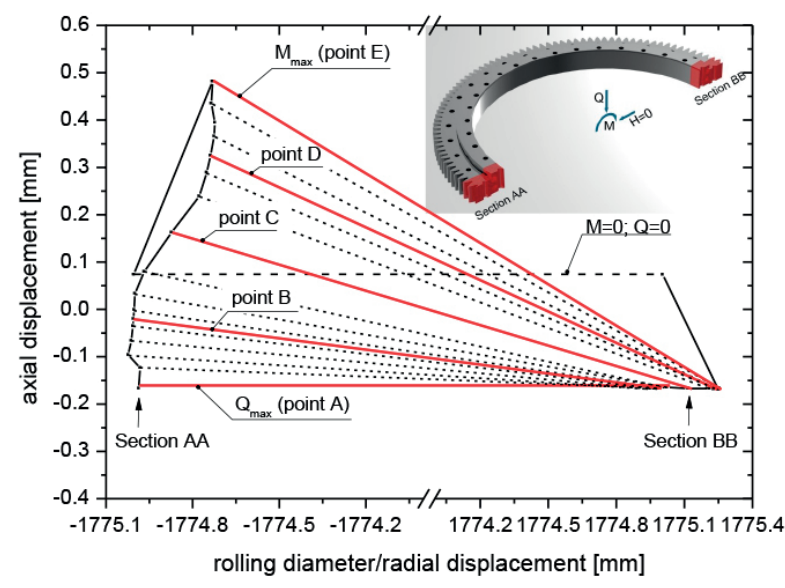

Figure 8 Next positions of the inner ring of the bearing for individual points $A, B, C, D$ marked in Figure 6

\section{Conclusion}

Realization of a correct presented method of computing the catalogue capacity of slewing bearings allows the bearing characteristics to be determined exactly. Modern methods of modelling and the development of the FEM software make it possible to construct numerical models of the rings relatively quickly, especially the application of super-elements to simulate the rolling parts.

The presented analysis allows the force distribution in the individual rows of the bearings to be exactly determined, which is impossible using analytical methods. The analytical methods are reduced for the bearing computations by the assumption of the non-deformability of the bearing rings. The computational modelling allows all constructional and technological changes introduced into the geometry of the real bearing, to be quickly verified and also allows the geometrical characteristics of the mounting structure of the bearing in a machine to be taken into account. The method of modelling the rolling elements, which

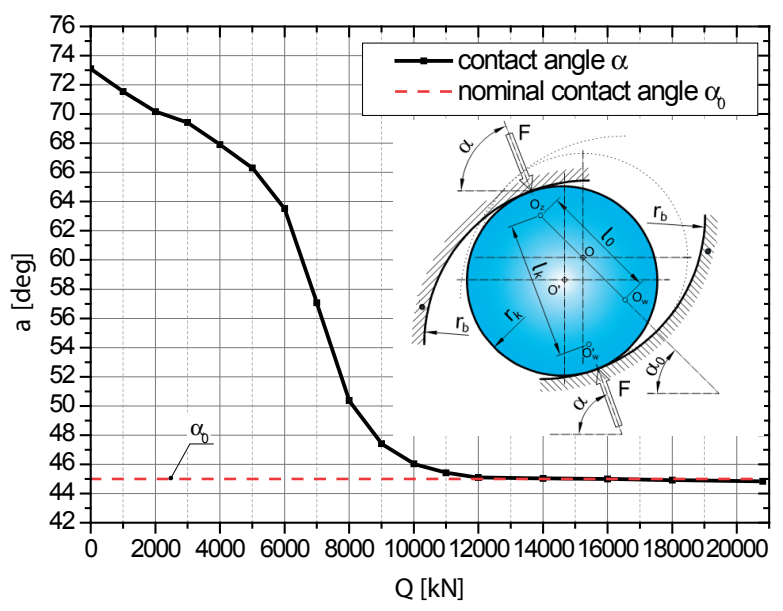

Figure 9 Ranges of changes in the contact angle in a double - row roller/ ball combination slewing bearing

are replaced by special elements (super-elements), is the key stage in the presented computational methodology. Both the structure of the super-element and its substitute characteristics can have a profound influence on the obtained results of computations. To obtain an adequate characteristic of the bearing capacity, one must take into account both phenomena occurring in the contact zone of the rolling elements and raceways and the influence of the method of the rolling element modelling in the FEM numerical model of a bearing.

The computations in the proposed method, using the ADINA software, can be successfully applied in any other software. Model of working machine and the slewing bearing is the most important part of the computations. Nowadays, the types of models of supporting structures have reached a certain standard in the design of new machines and equipment. Due to that, the determination of the total capacity of a bearing requires only the additional construction of the model of a slewing bearing. Notes contained in this paper and the usage of marked references in the bibliography should make it easier to work out such a model.

\section{References}

[1] KRYNKE, M., BORKOWSK,I S., SELEJDAK, J.: Analysis of Influence of Bearing Clearance on the Static Carrying Capacity of Multi - Row Slewing Bearings. Periodica Polytechnica Transportation Engineering, 42(1), 43-48, 2014.

[2] KRYNKE, M., MIELCZAREK, K.: Analysis of Causes and Effects Errors in Calculation of Rolling Slewing Bearings Capacity. Production Engineering Archives, 12(3), 38-41, 2016.

[3] BRANDLEIN, J., ESCHMANN, P., HASBERGEN, L., WEIGAND K.: Ball and Roller Bearings: Theory, Design and Application, 3 edition. Wiley 1999.

[4] ROTHER ERDE: Slewing Bering. Katalog 2016.

[5] ADINA. Theory and Modeling Guide, Volume 1: ADINA. ADINA R\&D, Inc., Watertown, 2004.

[6] SMOLNICKI, T., RUSINSKI, E.: Superelement - Based Modeling of Load Distribution in Large - Size Slewing Bearings. Journal of Mechanical Design, 129(4), 459-463, 2007. 
[7] KANIA, L.: Modelling of Rollers in Slewing Bearing Calculations with the Use of Finite Elements. Mechanism and Machine Theory, 41(11), 1359-1376, 2006.

[8] JASKOT, A., SPIEWAK, S:. Modeling of Selected Load - Bearing Structures Using the Truss and Beam Elements. Journal of Applied Mathematics and Computational Mechanics, 14(3), 37-47, 2015.

[9] SPIEWAK, S.: Methodology for Calculating the Complete Static Carrying Capacity of Twin Slewing Bearing. Mechanism and Machine Theory, 101, 181-194, 2016.

[10] KANIA, L., KRYNKE, M., MAZANEK, E. A.: Catalogue Capacity of Slewing Bearings. Mechanism and Machine Theory, 58, 29-45, 2012.

[11] KRYNKE, M., KANIA, L., MAZANEK, E.: Modelling the Contact Between the Rolling Elements and the Raceways of Bulky Slewing Bearings. Key Engineering Materials, 490, 166-178, 2012.

[12] KANIA, L., KRYNKE, M.: Computation of the General Carrying Capacity of Slewing Bearings. Engineering Computations, 30(7), 1011-1028, 2013. 